\title{
Online Anatomy education during COVID 19 pandemic period among pre-clinical Medical Students: An Experience of University of Peradeniya
}

Kosgallana $\mathrm{EW}^{1}$, Jayasankita $\mathrm{PN}^{1}$, Jayaweera $\mathrm{AK}^{1}$, Supunsara $\mathrm{HMG}^{1}$, Adikari $\mathrm{SB}^{1}$, Amaratunga $\mathrm{HA}^{1}$

${ }^{1}$ Department of Anatomy, Faculty of Medicine, University of Peradeniya

\begin{abstract}
\section{Objective}

The objective of this study was to evaluate the perception, attitudes, and barriers faced by students during the online anatomy course.
\end{abstract}

\section{Materials and methods \\ A descriptive cross-sectional study was carried using a questionnaire, based on available feedback questionnaires from the faculty and published questionnaires, pilot tested and finalized. It was distributed via Google-forms to 185 second-year students who had undergone 2 semesters of online teaching.}

\section{Results}

A total of 115 Google-forms were received. Females represented $50.9 \%$, with a mean age of $21.9 \pm 1.022$ years. Smartphones $(86 \%)$ were mainly used to access online material while mobile data $(79.8 \%)$ was the commonest method of internet access. Online learning tool usage was: Moodle-98.2\% Zoom-94.7\% and Youtube- $66.7 \%$. Attitudes towards online learning were positive $(77.2 \%)$ with prior preparation for teaching sessions as high as $97.4 \%$ and active participation in the online sessions (81.6\%). Majority preferred Moodle for online lectures (81.74\%), histology practical sessions $(89.57 \%)$ and slide projections $(82.74 \%)$ while for gross practical sessions it was Moodle (80.87\%) and Youtube $(41.74 \%)$. For tutorials (70.44\%) and discussions (76.52\%) majority preferred Zoom sessions. Of the respondents $57.9 \%$ feared lack of direct anatomy learning might have an impact on their clinical skills in future. The major problems of online learning were identified as lack of self-motivation, lack of onsite practicals, and increased screen time.

\section{Conclusion}

Though majority of participants agreed that onsite anatomy teaching and learning cannot be replaced by the online course, the attitude towards it appears to be mostly positive during the COVID-19 pandemic.

Key words: COVID-19, Anatomy, Preclinical, Online, Medical education

\section{Introduction}

The COVID 19 infection is a serious global health threat, continuing its spread across the world. It has caused a pandemic with a growing number of cases and considerable mortality rate, infecting more than 90 million 
Kosgallana EW, Jayasankita PN, Jayaweera AK, Supunsara HMG, Adikari SB, Amaratunga HA - Online Anatomy education during COVID 19 pandemic period among pre-clinical Medical Students: An Experience of University of Peradeniya

people worldwide from the end of 2019 going into 2021.

This situation has changed the day to day life of individuals throughout the world. Schools and universities had to be closed and education activities were discontinued as a part of health guidelines to prevent the spread of the disease.

However, education is a must for the betterment of a country and a society and prolonged periods without education will have a bad impact on the future. Therefore, educators and teachers had to use alternative methods of teaching and learning to overcome this issue and as a result internet and webbased teaching and learning came to play a major role in continuing education during the pandemic.

Online teaching is characterized as the use of computer technology to provide technologybased learning. Even though this type of teaching has been there ever since the discovery of the web it always placed a less important role to onsite teaching. However, with the closure of universities and schools around the world, learning management systems and conference platforms quickly became the main method of imparting knowledge to millions of students around the world. Online learning modalities encourage student-centered learning and they are more easily manageable during this Pandemic situation (1). Further, transition to complete online program may be a learning experience for both students and faculty (2).

In Sri Lanka the situation is similar and online learning system has become a compulsory part of the teaching and learning process for higher education. After the sudden closure of universities in the country with the spread of COVID -19, the government of Sri Lanka promoted online and other distance education methods as an alternative solution for continuing higher education.

Unlike developed countries, this was a big challenge for most government universities where mostly education concepts were delivered through onsite teaching methods. For some subjects online platforms were ideal and maybe even better. However, for medical education where they have to take decisions based on experience it was a bigger challenge. In situations where conclusions are arrived at based on observations, guidance of a lecturer seems essential.

However, Faculty of Medicine, University of Peradeniya has continued the academic program shifting quickly to online teaching preventing major disruption of educating medical graduates. Almost all the batches in the faculty are involved in the online academic program including pre-clinical batches.

Pre-clinical years form the base of the entire medical career of undergraduates and therefore any deficiency in delivering knowledge during this initial period can affect their entire future. First year students with fresh minds and a high degree of enthusiasm are energetic learners and need proper guidance for laying the foundation to their medical careers.

When it comes to pre-clinical years anatomy is one of the main subjects. It is a highly practically oriented subject which requires students to learn by dissecting cadavers, handling bones and looking at microscopic 
slides. Therefore, the anatomy teachers face a huge challenge in delivering the practical aspects of anatomy to students through online education tools.

Teaching sessions have covered theory, discussions and tutorials via conference platforms and learning management systems (LMS). Recorded lectures were uploaded to LMS with pdf version of handouts. While some lectures were delivered live via conference platforms. Gross Anatomy practicals were done by making video clips and uploading them to the LMS. However, the students have missed the opportunity of doing dissections step by step and couldn't feel the beauty and the depth of this very interesting subject.

Despite all these efforts there are obvious deficiencies and issues in delivering this subject via online platform compared to traditional anatomy education. Department of Anatomy, Faculty of Medicine, University of Peradeniya has decided to conduct this questionnaire-based survey to identify these problems.

The aim of this study is to assess the student perception of the current online teaching program, to understand the attitudes of students, their preferences and the barriers faced in learning anatomy via the online platform, with a view to improving the delivery of subject matter to preclinical medical students.

\section{Methodology}

This descriptive cross-sectional questionnaire based online survey was conducted from January $20^{\text {th }}$ to February $15^{\text {th }} 2021$, among second year students in the Faculty of Medicine, University of Peradeniya. Participation was completely voluntary and informed consent was taken from each participant.

This survey was conducted to assess the perception, attitudes, and barriers faced by students during the online anatomy course conducted during the pandemic period. A questionnaire was designed using available feedback questionnaires from the faculty and published questionnaires.

The questionnaire included 65 questions, and was divided into two sections. First section consisted of questions regarding the demographic characteristics of the participants. Second section was further divided in to 7 parts. The first part was based on accessibility of necessary facilities. The second part included 16 questions to evaluate the attitudes towards the online anatomy course. It consisted of questions using 5-point Likert scale (5-Strongly agree, 4-Agree for the most part,3-Undiceded, 2-Disagree for the most part, 1-Disagree entirely.). The other parts consisted of questions regarding preparation for online teaching activities, questions regarding active participation during online teaching activities, students view on methods of delivering anatomy content via online platforms and problems related to online learning. 
Kosgallana EW, Jayasankita PN, Jayaweera AK, Supunsara HMG, Adikari SB, Amaratunga HA - Online Anatomy education during COVID 19 pandemic period among pre-clinical Medical Students: An Experience of University of Peradeniya

The questionnaire was pilot tested on 5 final year students and edited accordingly. The finalized questionnaire was built into Googleforms. The consent form and the questionnaire were emailed to 185 second-year students who had undergone 2 semesters of online teaching.

Statistical data analysis was performed by using Microsoft excel and Minitab 17 statistical software.

\section{Results}

Out of the 185 questionnaires distributed a total of 115 were received. Age ranged from 19-25 years with a mean age of $21.9 \pm 1.022$ years. Gender distribution was male- $49.1 \%$ and female $50.9 \%$. Smartphones $(86 \%)$ tablets $(68.4 \%)$ and laptops $(41.2 \%)$ were used to access online material. Of the participants $79.8 \%$ used personal mobile data and $56.5 \%$ accessed personal Wi-Fi connections to connect to the net. Almost all students had their own devices and a good internet connection to access online content. The faculty LMS (Moodle) (98.2\%), conference platform (zoom) (94.7\%) and YouTube $(66.7 \%)$ were the commoner online tools used for learning.

\section{Attitude and Perception towards online learning/ teaching in Anatomy.}

Most of the participants (77.2\%) had positive attitudes towards the online anatomy course, while $19.3 \%$ had neutral attitudes. Most of the student found learning anatomy online to be comfortable $(70.1 \%)$ and their LMS to be well organized and user friendly $(87.7 \%)$. Of the participants, $47.45 \%$ felt that online learning in Anatomy should play a complementary role in the future while $35.1 \%$ were neutral to the idea. Most students $(82.45 \%)$ felt that online learning gave them more time to spend with their families. Most students (85.9\%) felt that the online anatomy course was used effectively during the COVID 19 pandemic and $57.9 \%$ mentioned that the online content and teaching sessions had improved the standard of anatomy teaching. Only $32.5 \%$ felt that their motivation for online learning was higher compared to onsite learning. Most $(62.3 \%)$ felt that they could manage their time better with online teaching. However, 57.9\% participants feared that the lack of direct onsite face to face anatomy learning might have an impact on their clinical knowledge in the future. Many of the participants (62.6\%) agreed that onsite anatomy teaching and learning cannot be replaced by the online course. Table 1 shows the statements used to assess the attitude towards online learning/ teaching in Anatomy. 
Kosgallana EW, Jayasankita PN, Jayaweera AK, Supunsara HMG, Adikari SB, Amaratunga HA - Online Anatomy education during COVID 19 pandemic period among pre-clinical Medical Students: An Experience of University of Peradeniya

Table 1: Statements used to assess the attitude towards online learning/ teaching in Anatomy.

1) I comfortable in learning Anatomy via online platforms.

2) I feel that online learning in Anatomy should play a complementary role in the future.

3) I feel that Moodle (LMS) is well organized and user friendly for teaching Anatomy.

4) I feel less stressed for online teaching in anatomy compared to onsite teaching.

5) I feel that I have got more time to be with my family because of online teaching.

6) I feel that online teaching is efficient for Anatomy compared to onsite teaching.

7) I feel that online teaching is used effectively for Anatomy during COVID 19 pandemic period.

8) I feel that increased use of online platforms for Anatomy improves standards of Anatomy education.

9) My motivation is high for online teaching in Anatomy compared to onsite teaching.

10) I feel independent during online learning compared to face to face Anatomy learning.

11) I am able to manage my time effectively and easily because of online teaching compared to onsite teaching.

12) I prefer online learning anatomy to onsite methods.

13) I believe that I could reduce my expenses spent on study materials because of online teaching.

14) I have a fear of getting low marks for anatomy because of online learning.

15) I feel that lack of direct anatomy learning will have an impact on my clinical knowledge in future.

16) I feel that onsite learning in anatomy cannot be replaced by online learning.

The percentage of students that mentioned they had prior preparation for teaching sessions was as high as $97.4 \%$ and active participation in the online sessions was $81.6 \%$. Student preferences on the delivery mode of different anatomy teaching components are given in table 2. 
Table 2: Student preferences on methods of delivery of anatomy components via online platforms.

\begin{tabular}{|c|c|c|c|c|c|}
\hline & $\begin{array}{c}\text { Conference } \\
\text { platform } \\
\text { (Zoom) }\end{array}$ & $\begin{array}{c}\text { LMS } \\
\text { (Moodle) }\end{array}$ & $\begin{array}{c}\text { Social } \\
\text { media } \\
\text { (Facebook) }\end{array}$ & $\begin{array}{c}\text { Social media } \\
\text { (WhatsApp) }\end{array}$ & YouTube \\
\hline Anatomy & $\begin{array}{c}55.6 \% \\
(64)\end{array}$ & $\begin{array}{c}81.74 \% \\
(94)\end{array}$ & $\begin{array}{c}1.74 \% \\
(2)\end{array}$ & $5.22 \%$ & $22.61 \%$ \\
Lectures & $20.0 \%$ & $80.87 \%$ & N/A & $2.61 \%$ & $41.74 \%$ \\
\hline Gross & $(23)$ & $(93)$ & $(3)$ & $(48)$ \\
\hline Mnatomy practical's & $10.43 \%$ & $89.57 \%$ & N/A & $4.35 \%$ & $25.22 \%$ \\
\hline Practical's & $(12)$ & $(103)$ & & $(5)$ & $(29)$ \\
\hline Tutorials & $70.44 \%$ & $51.30 \%$ & $2.61 \%$ & $6.96 \%$ & $4.35 \%$ \\
& $(81)$ & $(59)$ & $(3)$ & $(8)$ & $(5)$ \\
\hline Practice Slide & $37.39 \%$ & $82.74 \%$ & N/A & N/A & $16.52 \%$ \\
\hline Projections & $(43)$ & $(94)$ & & & $(19)$ \\
\hline Question and answer & $76.52 \%$ & $43.48 \%$ & $5.22 \%$ & $15.65 \%$ & $6.09 \%$ \\
discussions & $(88)$ & $(50)$ & $(6)$ & $(18)$ & $(7)$ \\
\hline
\end{tabular}

With regard to lectures most participants preferred the uploading of a video recording (42.1\%) or narrated PowerPoint (38.6\%) of the lectures with a PDF version of the lecture handout to the LMS.

Student perceptions on the mode of delivery of practical components in anatomy are given in figure 1 .

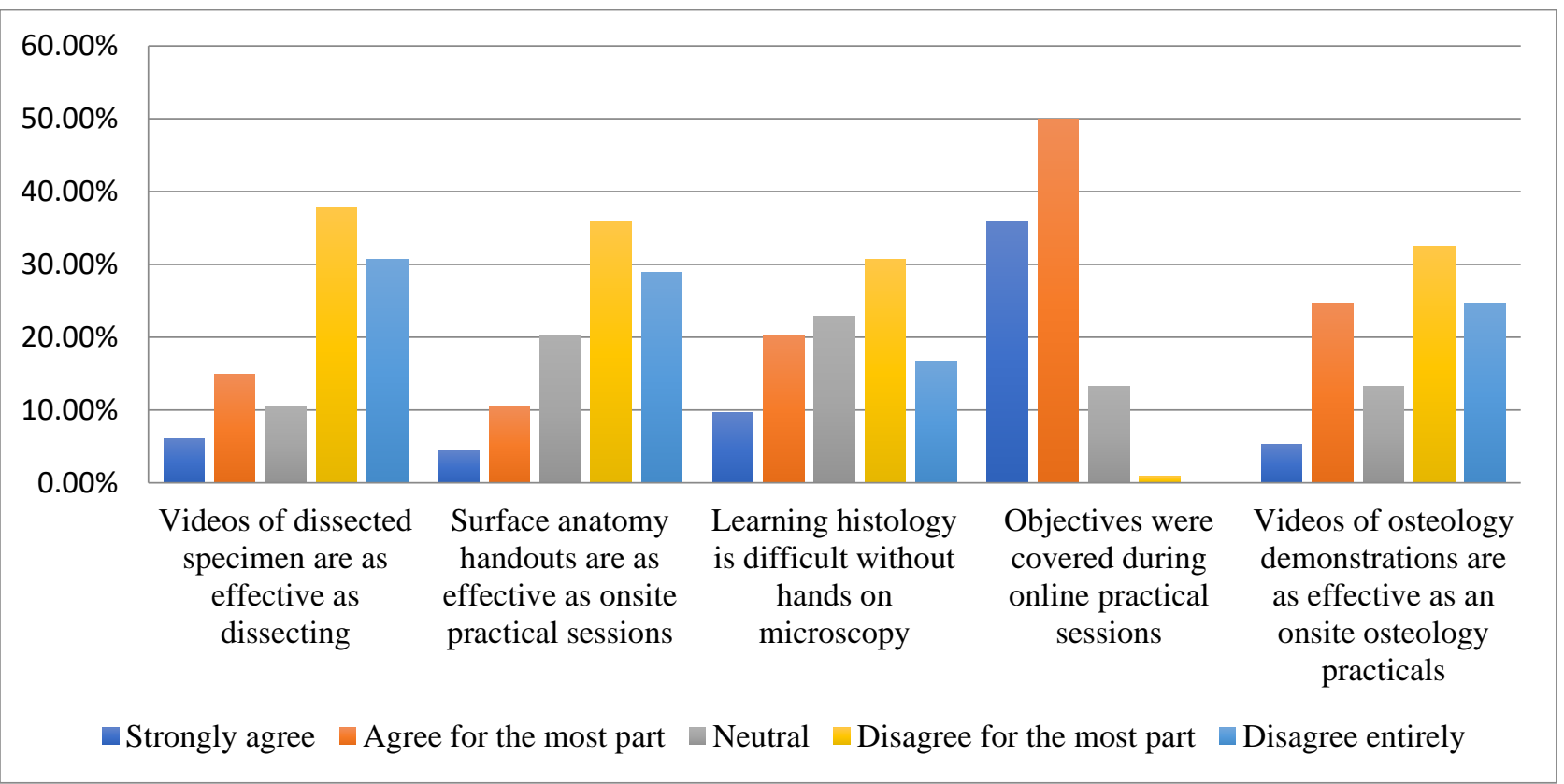

Figure 1: Student perceptions on the mode of delivery of practical components. 
Kosgallana EW, Jayasankita PN, Jayaweera AK, Supunsara HMG, Adikari SB, Amaratunga HA - Online Anatomy education during COVID 19 pandemic period among pre-clinical Medical Students: An Experience of University of Peradeniya

\section{Issues/ Barriers faced during the online Anatomy course.}

With regard to problems faced during the online course, $21.1 \%$ complained about the screen size of their device. Only $24.6 \%$ of the participants complained of poor internet connection. Respectively $15.8 \%$ and $13.2 \%$ complained about uncomfortable home environment and diminished freedom at home due to online learning. The time spent on learning via online platforms has significantly increased as expected. Previously only $10.5 \%$ engaged more than 4 hours per day to learn via online modes. However, during the pandemic time, it has increased up to $70.2 \%$.

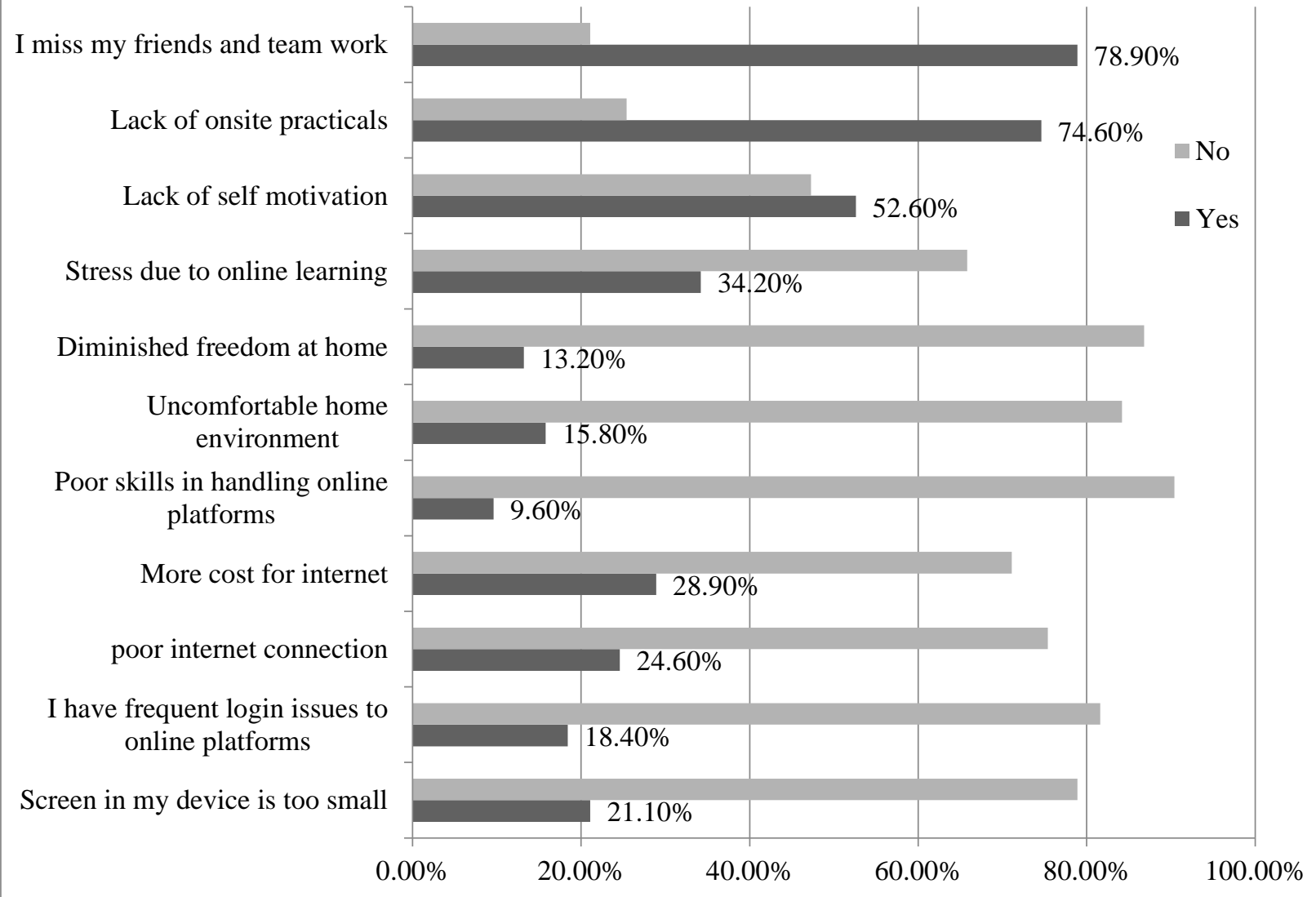

Figure 2: Main Problems faced during online learning.

Of the participants $49.1 \%$ faced health problems or discomfort due to prolonged screen time. Visual symptoms were more common among the respondents (83.9\%). According to respondents sleeping difficulties were complained by $36.2 \%$ and musculoskeletal related pain by $41.1 \%$ of the participants.

\section{Discussion}

Due to the COVID 19 infection, physical classroom sessions were suspended by different government regulations and universities had to assume an online based course. This transition was more difficult for disciplines such as anatomy due to its practical 
Kosgallana EW, Jayasankita PN, Jayaweera AK, Supunsara HMG, Adikari SB, Amaratunga HA - Online Anatomy education during COVID 19 pandemic period among pre-clinical Medical Students: An Experience of University of Peradeniya

nature of delivering content. Cadaver dissections, microscopy practical sessions, osteology demonstrations and practical sessions on surface anatomy play an integral part of anatomy teaching. Developing an online course to cover these practical aspects, while delivering lecture-based content was a daunting task for most anatomy teachers. The online anatomy course at Peradeniya was designed to deliver the lecture component as well as to imbibe at least a percentage of practical knowledge to students.

The main purpose of this study was to assess the perception, attitudes, and barriers faced by students during the period of online anatomy teaching. Although this area has been evaluated in other countries, researchers consider this the first exploration of the topic in Sri Lanka.

Most of the participants in the current study had positive attitudes towards online learning during the pandemic (77.2\%). However, $62.6 \%$ of the participants perceived that onsite teaching cannot be replaced by online teaching. Similar findings were reflected by other studies which reveal that although distance anatomy education proves valuable during the pandemic, it is less efficient than traditional methods especially with regard to practical lessons $(3,4,5)$. This demonstrates that hands on experience in understanding the anatomical three-dimensional structure and relations cannot be completely replaced by virtual methods.

Students felt that video demonstrations of prosected specimens or dissections were not as effective as cadaveric dissections at the laboratory. They preferred onsite surface anatomy and osteology practical sessions to video demonstrations or practicing on one's self at home. However, it appeared as if they preferred video demonstrations of histology slides to actual microscopic examination of slides. Even though the majority preferred onsite practical sessions they agreed that all objectives for the practical sessions were covered by the online course.

Findings of our study revealed a significant increase in the time spent on online platforms for learning before and during the pandemic time as expected. A similar study among UK medical students revealed that the percentage of students using online platforms for more than 15 hours per week increased from $7.35 \%$ prior vs $23.56 \%$ during the pandemic (6). Prolonged screen time could be a cause of health problems such as visual symptoms, sleep disturbances and musculoskeletal pain as reported by the students. Research studies have found evidence between prolonged screen time and visual health problems (7). Awareness of these issues could be considered as the first step in remedial actions such as regular breaks from screen time and stretching exercises in between online sessions.

Our study reveals an overall positive attitude towards online learning among the pre-clinical students. The online delivery of lectures, gross anatomy practicals and microscopy practicals were well received by most even though the majority agreed that onsite lessons cannot be replaced by online methods of teaching. The lack of hands-on experience in learning anatomy may have a disadvantage in the deep understanding of the subject when applying 
knowledge in the clinical setting. A study in

Saudi Arabia reported that videos and images would not substitute practical sessions $(68.4 \%)$

(8).

COVID-19 pandemic has disrupted face-toface teaching in medical schools all over the world. This study reflects that the Department of Anatomy has successfully transitioned their educational environment to online teaching and assessments. One of the main implications was identified as preclinical students missing the hand on experience during their preclinical years $(57.9 \%)$. Similar results were reflected by a study by Gaur et al., 2020 (9).

The major problems of online learning were identified as lack of self-motivation (52.6\%), loss of peer learning (78.9\%) and lack of onsite practicals $(74.6 \%)$. In a study carried out among medical students in Libya the main problems faced by the participants were financial issues and poor quality of internet connection which were not reported by the majority in our study (10).

As the response rate was $62.16 \%$, the attitudes and perceptions of all students could not be accurately assessed, which can be considered as a limitation of this study. It is further questionable whether this was due to issues with regard to online communication.

Even though online education has proven to be well perceived by the students during the pandemic period educators must be vigilant in identifying problems related to online learning and addressing them when designing and implementing new online anatomy courses for effective online education.

\section{Acknowledgement}

None

\section{Conflict of interest}

None

\section{Corresponding Author}

E.W. Kosgallana

C-40, Upperhantana Quarters,

University of Peradeniya, Peradeniya.

Tel: 0775719942

E-mail: warukos@gmail.com

\section{BY 4.0}

This is an Open Access article distributed under the terms of the Creative Commons Attribution 4.0 license (unless stated otherwise) which permits unrestricted use, distribution and reproduction in any medium, provided the original work is properly cited. Copyright is retained by the author(s).

\section{References}

1. Mukhtar, K., Javed, K., Arooj, M., \& Sethi, A. (2020). Advantages, limitations and recommendations for online learning during covid-19 pandemic era. Pakistan Journal of Medical Sciences, 36(COVID19-S4), S27S31.

https://doi.org/10.12669/pjms.36.COVID19 -S4.2785 
2. Singh, K., Gaur, U., Hall, K., Mascoll, K., Cohall, D., \& Azim Majumder, M. (2020). Teaching anatomy and dissection in an era of social distancing and remote learning. Advances in Human Biology, 10(3), 90. https://doi.org/10.4103/aihb.aihb_87_20

3. Roy, H., Ray, K., Saha, S., \& Ghosal, A. K. (2020). A Study on Students' Perceptions for Online Zoom-app based Flipped Class Sessions on Anatomy Organised during the Lockdown Period of COVID-19 Epoch.

Journal of Clinical and Diagnostic

Research, 1-4.

https://doi.org/10.7860/jcdr/2020/44869.13 797

4. Ortadeveci, A., Ermez, M.N., Oz, S. et al. A survey study on distance anatomy education: challenges unique to anatomy. Surg Radiol Anat (2021). https://doi.org/10.1007/s00276-021-02772$\mathrm{Z}$

5. Cheng, X., Chan, L. K., Pan, S. Q., Cai, H., Li, Y. Q., \& Yang, X. (2021). Gross Anatomy Education in China during the Covid-19 Pandemic: A National Survey. Anatomical Sciences Education, 14(1), 818. https://doi.org/10.1002/ase.2036

6. Dost, S., Hossain, A., Shehab, M., Abdelwahed, A., \& Al-Nusair, L. (2020). Perceptions of medical students towards online teaching during the COVID-19 pandemic: A national cross-sectional survey of 2721 UK medical students. BMJ Open, 10(11), 1-10. https://doi.org/10.1136/bmjopen-2020042378
7. Wong, C. W., Tsai, A., Jonas, J. B., OhnoMatsui, K., Chen, J., Ang, M., \& Ting, D. (2021). Digital Screen Time During the COVID-19 Pandemic: Risk for a Further Myopia Boom? American journal of ophthalmology, 223, 333-337. https://doi.org/10.1016/j.ajo.2020.07.034

8. Khlood Mohammed Mehdar (2020). Students' Attitudes as Regard to Distance Learning of Anatomy Courses throughout COVID-19 Pandemic Lockdown Period among Medicine and Paramedical Faculties of Najran University, Saudi Arabia. Universal Journal of Educational Research, 8(11B), 6166 - 6172. DOI:

10.13189/ujer.2020.082253.

9. Gaur, U., Majumder, M. A. A., Sa, B., Sarkar, S., Williams, A., \& Singh, K. (2020). Challenges and Opportunities of Preclinical Medical Education: COVID-19 Crisis and Beyond. SN Comprehensive Clinical Medicine, 2(11), 1992-1997. https://doi.org/10.1007/s42399-020-005281

10. Alsoufi, A., Alsuyihili, A., Msherghi, A., Elhadi, A., Atiyah, H., Ashini, A., Ashwieb, A., Ghula, M., Ben Hasan, H., Abudabuos, S., Alameen, H., Abokhdhir, T., Anaiba, M., Nagib, T., Shuwayyah, A., Benothman, R., Arrefae, G., Alkhwayildi, A., Alhadi, A., ... Elhadi, M. (2020). Impact of the COVID-19 pandemic on medical education: Medical students' knowledge, attitudes, and practices regarding electronic learning. PLoS ONE, 15(11 November), 1-20. https://doi.org/10.1371/journal.pone.024290 5 